\title{
Artigos
}

\section{Produção científica no empreendedorismo rural relacionado ao}

\section{turismo}

\section{Scientific production on tourism-related rural entrepreneurship \\ Producción científica sobre emprendimiento rural relacionado con el turismo}

\author{
Ivaneli Schreinert dos Santos ${ }^{1}$, Camila Elisa dos Santos Alves², Homero Dewes 3 \\ ${ }^{1}$ Centro de Pesquisa Interdisciplinar em Agronegócio (CEPAN), Universidade Federal do Rio Grande do Sul (UFRGS), \\ Porto Alegre, Brasil. Endereço atual: Universidade de São Paulo (USP), São Paulo, SP, Brasil. \\ 2 Centro de Pesquisa Interdisciplinar em Agronegócio (CEPAN), Porto Alegre, RS, Brasil. \\ ${ }^{3}$ CEPAN e Departamento de Biofísica, Instituto de Biociências (UFRGS), Porto Alegre, RS, Brasil.
}

\section{Palavras-chave:}

Desenvolvimento Rural. Sustentabilidade rural.

Gestão rural.

Agronegócio.

Multi-funcionalidade rural.

\section{Keywords:}

Rural development; Rural sustainability; Rural management; Agribusiness; Rural multi-functionality.

Palabras clave:

Desarrollo Rural. Sostenibilidad rural. Manejo rural. Agronegocios.

Multifuncionalidad rural.

Revisado em pares.

Recebido em: 21/05/2020.
Resumo

Este estudo teve como objetivo compreender a produção científica sobre o Empreendedorismo Rural e a sua ligação ao setor de Turismo. Para tanto, foi utilizado o método de mineração de texto com artigos e revisões. Por meio de uma estrutura de análise específica, extraíram-se palavras dimensionais que caracterizam as temáticas: Empreendedorismo Social, Estratégias de Negócio, Gênero, Impacto Socioeconômico Local, Inovação e Competitividade, Migração e Tecnologias. Esses temas foram previamente selecionados a partir de uma revisão sistemática. Os resultados indicam a Índia como país que mais estuda sobre Empreendedorismo Rural, e onde a temática Gênero tem maior relevância. Contudo, notou-se que o setor do turismo não é expressivo nesta região. É na Espanha que a atividade turística demonstra uma ligação mais forte com o empreendedorismo no meio rural. As áreas do conhecimento evidenciam que os estudos estão concentrados em Ciências Sociais e Negócios, Gestão e Contabilidade. Em suma, esse trabalho apresentou um estudo a fim de auxiliar na melhor compreensão da evolução das pesquisas sobre turismo como forma de empreender no meio rural.

\section{Abstract}

This study aimed to understand the scientific production on Rural Entrepreneurship and its connection to the Tourism sector. For that, the text mining method with articles and reviews was used. Through a specific analysis structure, dimensional words were extracted that cha-racterize the themes: Social Entrepreneurship, Business Strategies, Gender, Local Socioeco-nomic Impact, Innovation and Competitiveness, Migration, and Technologies. These themes were previously selected from a systematic review. The results indicate India as the country that most studies on Rural Entrepreneurship, and where the theme of Gender has greater relevance. However, it was noted that the tourism sector is not significant in this region. It is in Spain that tourism activity shows a stronger link with entrepreneurship in rural areas. The areas of knowledge show that the studies are concentrated in Social Sciences and Business, Management, and Accounting. In short, this work presented a study to assist in a better un-derstanding of the evolution of research on tourism as a way of undertaking in rural areas.

\section{Resumen}

El objetivo de este estudio fue comprender la producción científica sobre emprendimiento rural y su conexión con el sector turístico. Para eso, se utilizó el método de minería de texto con artículos y reseñas. A través de una estructura de análisis específica, se extrajeron palabras dimensionales que caracterizan los temas: emprendimiento social, estrategias empresariales, género, impacto socioeconómico local, innovación y competitividad, migración y tecnologías. Estos temas fueron seleccionados previamente de una revisión sistemática. Los resultados indican la India como el país que más estudia sobre emprendimiento rural, y donde el tema de género tiene mayor relevancia. Sin embargo, se observó que el sector turístico no es significativo en esta región. Es en España donde 
Aprovado em: 12/07/2020.

Editor:

Glauber Eduardo de Oliveira Santos

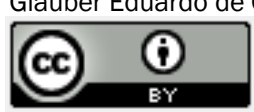

la actividad turística muestra un vínculo más fuerte con el espíritu empresarial en las zonas rurales. Las áreas de conocimiento muestran que los estudios se concentran en Ciencias Sociales y Negocios, Gestión y Contabilidad. Así, este trabajo presentó un estudio con el fin de ayudar a comprender mejor la evolución de la investigación sobre el turismo como una forma de emprender en las zonas rurales.

Como Citar: Santos, I. S.; Alves, C. E. S.; Dewes, H. (2021). Produção científica no empreendedorismo rural relacionado ao turismo. Revista Brasileira de Pesquisa em Turismo, São Paulo, 15 (3), e-2037, maio/ago. http://dx.doi.org/10.7784/rbtur.v15i3.2037

\section{CONSIDERAÇÕES INICIAIS}

O cenário do agronegócio vem se transformando através do tempo. Tal mudança não ocorre apenas no contexto econômico, mas também social e ambiental, e acaba por trazer novos elementos aos espaços rurais. Segundo Liang (2017), o crescimento agrícola tem sido atenuado pela concorrência, intensificação e especialização, resultando em um declínio gradual, fazendo com que a agricultura precise, portanto, se adaptar às transições da sociedade na economia e nas políticas governamentais, a fim de desenvolver práticas mais sustentáveis.

Antes dessas transformações, o meio rural era, tradicionalmente, visto como um espaço de produção agropecuária e reconhecido como um lugar com dinâmicas limitadas e baixa diversificação em tecnologias e produtos, quando comparado aos centros urbanos. Isso poderia levar a crer que o empreendedorismo na área rural seria menos desenvolvido, e com pouca inovação. Entretanto, as constantes mudanças nos mercados passaram a induzir os produtores rurais a se adaptarem às novas dinâmicas e novos hábitos de consumo. 0 que modificou a demanda, impondo a necessidade da proteção ambiental, a preocupação com os impactos socioeconômicos e gerenciamento da cadeia como um todo, entre outros fatores estratégicos para a sustentabilidade dos negócios.

À vista disso, é reconhecido por profissionais, cientistas e políticos que os trabalhadores do campo precisam cada vez mais do empreendedorismo, de uma boa gestão e de habilidades que sejam eficazes para a sustentabilidade de suas respectivas atividades (Mcelwee, 2008; Pyysiäinen, Alistair, \& McElwee, 2006).

Atualmente é percebido que o empreendedorismo no meio rural não é apenas uma ilusão ou uma simples campanha publicitária, mas tem sim um impacto profundo no crescimento e na sobrevivência dos negócios (Lans, Verstegen, \& Mulder, 2011; Verhees, Kuipers, \& Klopcic, 2011). Dessa forma, o empreendedorismo rural é definido como um forte elemento para o desenvolvimento econômico rural, garantindo o acréscimo de valor aos recursos nas zonas rurais, o qual inclui diferentes atividades, como agricultura, comércio e indústria (Alabi \& Famakinwa, 2019).

Ou seja, o contexto rural passou a dar espaço para o desenvolvimento de atividades não agrícolas. Assim, a função produtiva, antes restrita apenas à agricultura, passou a abranger diversas outras atividades, como o artesanato e o processamento de produtos naturais e outras ligadas à conservação ambiental e ao turismo rural (Kageyama, 2004).

Assim, percebe-se um aumento na relevância da atividade turística como forma de empreender no meio rural. Por meio do turismo rural é possível combinar a produção agrícola com as visitações, promovendo, de acordo com Sharpley e Vass (2006) o uso efetivo da mão-de-obra do agronegócio e a geração de uma fonte de renda adicional. Logo, o turismo rural transforma-se em um segmento promissor dentro do agronegócio, sendo uma opção interessante de atividade aos empreendedores do meio rural.

Devido à importância do turismo no âmbito rural, torna-se necessário entender a evolução do conhecimento e da produção científica, pois essa é a base principal para o progresso. A partir da evolução científica é que o ser humano consegue superar os seus problemas e evoluir em diversos sentidos. Entender essa evolução do conhecimento é imprescindivel, pois é preciso detectar quais são os problemas e compreende-los, para assim poder solucioná-los ou pelo menos controlá-los, ao invés.

Diante disso, o presente trabalho teve como objetivo abordar a evolução científica da temática do turismo rural como forma de empreender, para que assim fosse possivel aprofundar o conhecimento sobre alguns elementos que estão inseridos nestes tópicos. Ressalta-se que o desenvolvimento da ciência demonstra que dificuldades podem sim ser manipuladas e solucionadas constantemente, fazendo com que o papel da ciência na humanidade seja importante para o progresso da população mundial. 


\section{MATERIAL E MÉTODOS}

Este estudo utilizou o processo de Mineração de Textos, com base na divisão proposta por Hippner e Rentzmann (2006). 0 processo utilizado consiste em seis etapas, que podem ser vistas com maior detalhamento na Figura 1.

Figura 1 - 0 processo completo utilizado no presente trabalho para a realização da mineração de textos

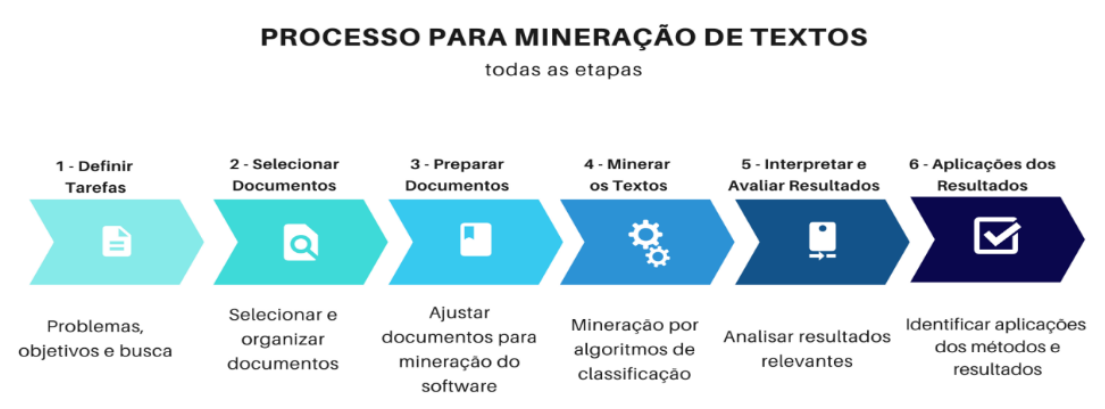

Fonte: Adaptada de Hippner e Rentzmann (2006).

\subsection{Definição das Tarefas e Delimitação da Pesquisa}

O conceito de empreendedorismo relacionado ao contexto rural voltou a ser estudado mais recentemente e, através das modificações ocorridas no campo, foi proposto o "empreendedorismo rural", que passa a abranger mais atividades, para além das agrícolas, o que inclui e evidencia a atividade de turismo no meio rural. Devido a isto, o presente estudo optou por utilizar como objeto de estudo o "Empreendedorismo Rural" e a sua relação com o "Turismo Rural". Foi analisado, em um primeiro momento, o Empreendedorismo Rural e, logo após, as pesquisas dentro deste tema que estavam relacionadas ao Turismo.

Definido o delineamento da pesquisa, foi realizada a busca, no mês de junho de 2019, nas bases de dados SciVerse Scopus ${ }^{\circledR}$ de propriedade da Editora Elsevier e na Web of Science ${ }^{\circledR}$ (Institute for Scientific Information Knowledge). Para tanto, utilizou-se a expressão Entrepreneur* And Rural, feita no idioma inglês por ser uma base internacional. $O$ asterisco colocado tem como função buscar palavras derivadas, ou seja, com outros radicais. $O$ And tem a função de somar, assim há obrigatoriedade de ambas as palavras estarem presentes nas pesquisas encontradas.

A pesquisa foi delimitada do período de 1999 até junho de 2019, período que a temática teve maior expressividade nas pesquisas. Ademais, foram incluídos todos os documentos em formato de artigo científico ou revisão.

\subsection{Selecionar documentos}

Nesta pesquisa foram encontrados 2.532 documentos referentes ao empreendedorismo rural, estes passaram por um processo de filtragem, a partir da leitura dos títulos, resumos, palavras-chave e metodologia. Destes foram eliminados 184 estudos, pois não contemplavam o tema de empreendedorismo rural, restando um total de 2.348 documentos, os quais foram tabelados e classificados.

Além disso, verificou-se quais documentos abordavam apenas o meio rural e quais contemplavam também o meio urbano. Foram encontrados 1.981 estudos no primeiro caso e 351 no segundo, demonstrando que a maioria era focada exclusivamente no meio rural. Destes documentos, 288 eram referentes ao setor de turismo, logo após, este conjunto de dados também foi analisado separadamente (Figura 2).

Após essa etapa da pesquisa, revelou-se, a partir das leituras, que havia sete temas expressivos, pois 1.220 documentos estavam relacionados a tais temas, ou seja, mais da metade do total. Em vista disso, decidiu-se utilizar a Mineração em Textos, por ser considerada uma técnica inteligente para o tratamento de um grande volume de informações (Talamini, Wuhbben, Padula, \& Dewes, 2013). Sendo possível, a partir dela, entender melhor como os temas em questão estariam dispostos dentro da produção cientifica do empreendedorismo rural e do turismo.

Após a seleção e organização dos dados, é necessário realizar os ajustes dos documentos para o software e a confecção dos dicionários de palavras (d-words). As listas de palavras-chave que ocorrem com frequência dentro de um determinado tema são chamadas de dicionários. 
Figura 2 - Esquema das classificações realizadas com os documentos científicos sobre empreendedorismo rural, no período de 1999 até junho de 2019, demonstrando a quantidade encontrada para cada item.

2.348 ARTIGOS E REVISŌES CIENTIFICAS SOBRE EMPREENDEDORISMO RURAL

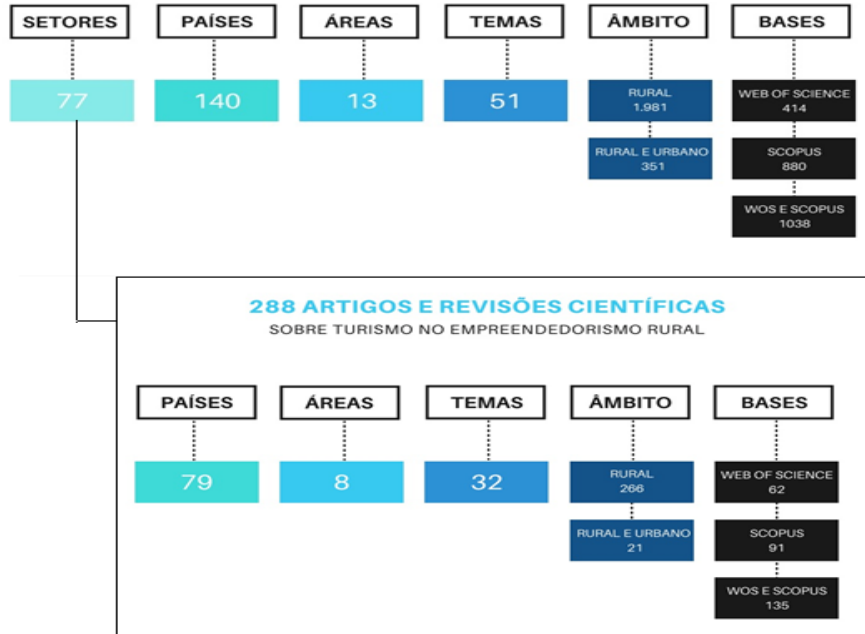

Fonte: Elaborado pelos autores (2019).

O presente estudo analisou sete temas expressivos identificados previamente a partir de uma revisão sistemática e foram criados, desta forma, sete dicionários de palavras distintos com intuito de caracterizar cada um destes tópicos. Os temas analisados foram: Empreendedorismo Social, Estratégias de Negócio, Gênero, Impacto Socioeconômico Local, Inovação e Competitividade, Migração e Tecnologias. Para confecção dos dicionários foi feita uma pesquisa nas bases de dados referente a cada um destes assuntos, utilizando as mesmas delimitações feitas anteriormente, porém, mudando os termos de busca.

Os documentos encontrados foram tabulados utilizando o título, resumo e palavras-chave de todos eles, obtendo,dessa forma, sete tabelas distintas, as quais foram separadamente ajustadas e transferidas para o software QDA Miners ${ }^{\circledR}$. Em seguida, uma contagem de palavras foi obtida com o módulo WordStat ${ }^{\circledR}$ do SIMStats ${ }^{\circledR}$. Este software calculou a frequência de cada palavra e a taxa TF*IDF (frequência do termo multiplicada pela frequência inversa do documento). De acordo com Provales (2006), quanto mais vezes um termo ocorre em um documento, mais representativo ele é no conteúdo do documento.

A partir da análise destas listas de frequências, foram selecionadas as palavras que mais caracterizavam cada um dos temas e incluídas nos conjuntos de regras. Estas são baseadas na ocorrência conjunta dos termos, o software WordStat ${ }^{\circledR}$ permite a construção das regras nos dicionários a partir de comandos operacionais, utilizando operações booleanos com AND, OR e NOT e de proximidade BEFORE, AFTER e NEAR. E o símbolo “@” se faz presente antes da palavra para indicar que foi inserida uma regra.

Deste modo, foi possível criar sete listas diferentes, as quais foram ajustadas de acordo com o contexto e, posteriormente, cada uma delas foi testada. Para realização deste teste foi utilizada a classificação realizada com os documentos encontrados na primeira busca referente ao empreendedorismo rural, como descrito anteriormente. Esses documentos passaram por uma revisão a partir de uma leitura prévia e foram identificados 51 temas diferentes.

Assim, foram selecionados os conjuntos de documentos que estavam classificados nos sete temas mais expressivos e, com auxílio do software WordStat, analisados a partir dos dicionários de palavras. 0 cruzamento destes dados foi feito para verificar se os dicionários estavam com as palavras ajustadas ao tema, demonstrando se seriam eficazes para sua identificação. As palavras que apareciam em comum em todos os conjuntos foram excluídas.

\subsection{Mineração dos Textos}

No processo de Mineração em Textos, o módulo Wordstat ${ }^{\circledR}$ realiza uma varredura nos textos eletrônicos que compõem as bases de dados a serem analisadas, nelas identificando a presença dos termos nos Dicionários de 
Palavras. Neste processo, é possível dimensionar, a partir destes resultados quantitativos gerados pelo software, os temas dentro desses documentos.

Após a construção dos sete dicionários, foi realizada a extração do conhecimento da produção científica sobre o empreendedorismo rural. Nesta extração, além da análise temporal, foi possível relacionar os temas aos países onde ocorreram os estudos, à área do conhecimento e aos setores de negócios.

Em seguida foi analisado o grupo de documentos que estava ligado ao setor do turismo. Ou seja, foram selecionados dentro destes dados do empreendedorismo rural todos os artigos e revisões que estudavam alguma atividade ou empreendimento relacionados diretamente com o turismo.

\section{RESULTADOS E DISCUSSÃO}

Nos últimos 4 anos, percebe-se um aumento significativo de interesse científico pelo tema de empreendedorismo ligado ao contexto rural. A evolução da quantidade de pesquisas sobre o tema pode ser visualizada na Figura 3.

Figura 3 - Evolução do número de publicações de trabalhos científicos, nas plataformas Scopus e Web of Science, com o tema de Empreendedorismo Rural

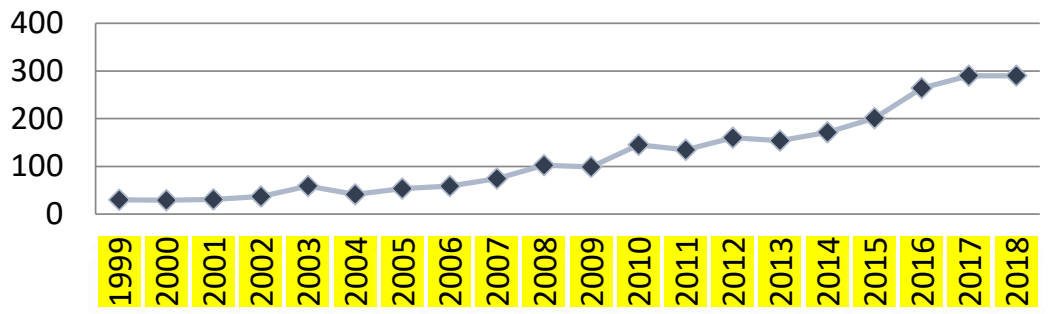

Fonte: Elaborado pelos autores (2019).

\subsection{Empreendedorismo Rural}

Dessa forma, optamos por estudar a temática do turismo no contexto do empreendedorismo rural. A primeira análise foi referente aos temas mais abordados dentro do Empreendedorismo Rural. Foram dimensionadas as frequências desses na produção científica analisada (Figura 4).

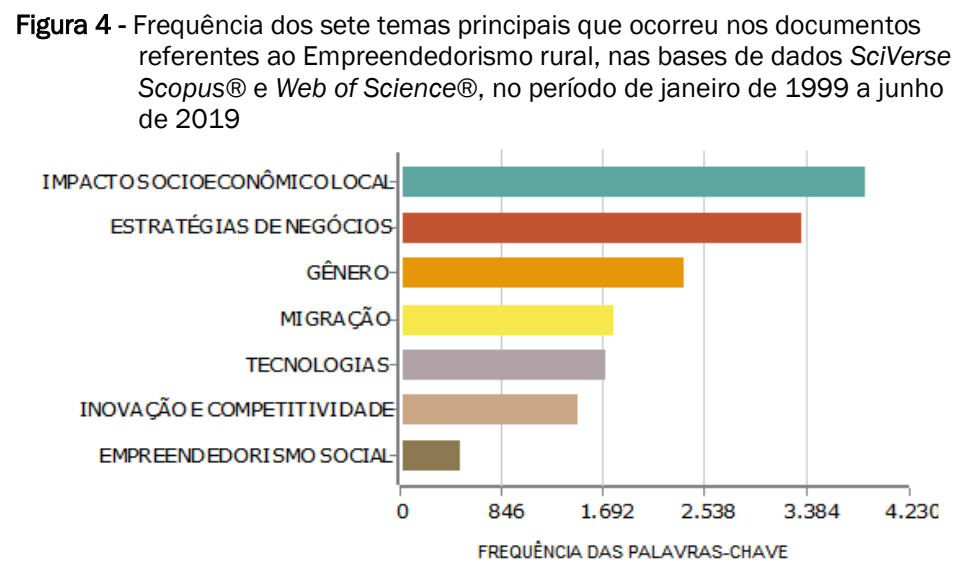

Fonte: Elaborado pelos autores (2019).

O tema mais expressivo foi o de Impacto Socioeconômico Local. Os artigos e revisões, em sua maioria, abordam ou avaliam transformações ocorridas na sociedade e economia a partir do empreendedorismo. Visto que, segundo Baumol (1996), o empreendedorismo é visto como um mecanismo econômico que pode induzir o crescimento socioeconômico. Por este motivo, segundo Honig (2016) o empreendedorismo se torna a sustentação de discursos de campanha política. E não é de se surpreender que seja o Impacto Socioeconômico Local o tema com maior frequência neste caso, uma vez que artigos também costumam trazer casos de localidades específicas e estudos sobre transformações da sociedade e economia destas regiões.

O segundo termo com mais aparições é Estratégias de Negócio, tema que costuma estar presente nos livros de empreendedorismo. Ao analisar livros reconhecidos da área do empreendedorismo e com expressivo número de 
citações nos artigos científicos, como "Handbook Of Entrepreneurship: Research, Entrepreneurship An Interdisciplinary Survey and Introduction" de Acs e Audretsch (2005), "Creativity And Innovative Business Models" de Burger-Helmchen (2012) e "Entrepreneurship And Economic Growth" Audretsch, Lehmann e Keilbach (2006), percebe-se que este tópico se faz presente nos estudos da área, talvez pelo fato desses livros terem como público alvo os empreendedores ou os aspirantes a empreendedores, que tendem a costumam preferir ensinamentos mais práticos sobre o funcionamento dos negócios.

Acs e Audretsch (2005), Burger-Helmchen (2012) e Audretsch, Lehmann e Keilbach (2006) destacam as dimensões de inovação e competitividade e tecnologias. Entretanto, nos artigos e revisões científicas sobre Empreendedorismo Rural, os temas de Gênero e Migração vêm antes. Logo, há um maior interesse nessas questões sociais dentro da academia.

De acordo com Tomazzoni (2016), os empreendedores podem ser voluntários, aqueles que têm motivação para empreender, ou involuntários, aqueles que são forçados a empreender por motivos alheios à sua vontade. Demonstrando que, por muitas vezes, as pessoas são levadas a tornarem-se empreendedoras devido às circunstâncias sociais.

Sendo assim, depara-se com um conjunto de estudos que acaba por colocar o empreendedorismo como uma espécie de ferramenta, a qual teria como função auxiliar na resolução ou diminuição de problemas sociais, como a questão de desigualdade de gênero e o êxodo rural, que é caso mais evidente dentro das pesquisas que abordaram a migração nas pesquisas analisadas sobre Empreendedorismo Rural.

Para Dias, Rodrigues e Ferreira (2019) existem várias questões interessantes para analisar dentro da literatura do empreendedorismo agrícola, e um dos tópicos mais importantes para estes autores seriam justamente estes temas citados. Nesse sentido, visou-se analisar outros aspectos dentro dos estudos científicos, como a evolução destes temas através dos anos. Neste caso, foi contabilizado até 2018, pelo fato de o ano de 2019 ainda não ter encerrado antes do término da presente pesquisa (Figura 5).

Figura 5 -Evolução dos sete temas principais que ocorreu nos documentos referentes ao Empreendedorismo rural, nas bases de dados SciVerse Scopus ${ }^{\circledR}$ e Web of Science ${ }^{\circledR}$ no período de 1999 até 2018

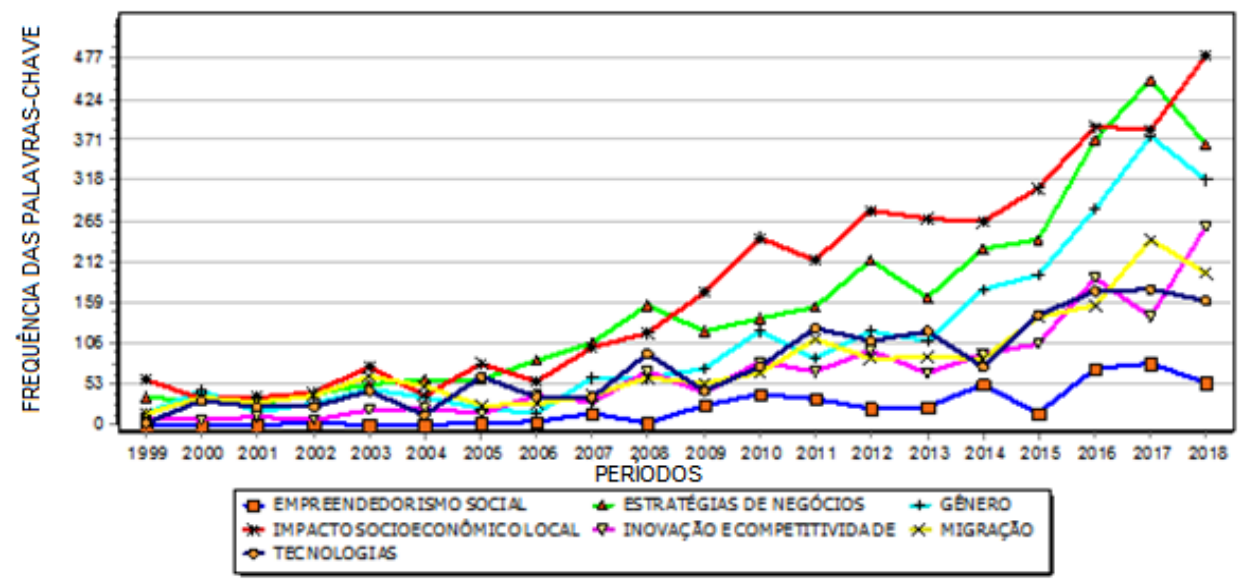

Fonte: Elaborado pelos autores (2019).

Percebe-se que o tema do Impacto Socioeconômico Local se manteve como o mais abordado na maioria dos anos, sendo ultrapassado poucas vezes pelo tópico Estratégias de Negócios. Importa reforçar que as transformações ocorridas na sociedade e na economia de uma localidade através do empreendedorismo foram, durante anos, e seguem sendo o assunto de maior interesse científico.

A partir do ano de 2014 o tema de Gênero passa a destacar-se, junto dos temas de Impacto Socioeconômico Local e Estratégias de Negócio, como os três principais assuntos. É possível relacionar aqui o contexto internacional referente aos movimentos sociais ligados ao feminismo, teoria que sustenta a igualdade política, social e econômica de ambos os sexos. Ao longo da história mulheres vêm organizando-se de diversas maneiras e em diferentes momentos. Em alguns desses momentos, contudo, ocorrem acúmulos de reivindicações e conquistas, sendo chamados de "ondas feministas", que são momentos históricos relevantes de efervescência na sociedade e na academia, onde determinadas pautas e questões das mulheres se insurgem e dominam o debate. 
A "primeira onda" se refere ao movimento sufragista inicial, luta pelo direito do voto feminino, que se originou na década de 1850 (Crawford, 1999). A "segunda onda" é do movimento feminista radical (raiz) das décadas de 1960 a 1980, fortemente influenciada pela "The Feminine Mystique" de Friedan (1963), com uma série de estudos focados na condição da mulher e contra estereótipos. A "terceira onda" é da década de 1990 em defesa da liberdade individual de cada mulher e liberdade de escolha (Gillis, Howie, \& Munford, 2004).

No ano 2012 emergiu a "quarta onda feminista", a qual é definida pela tecnologia, a internet associada às redes sociais, como Facebook, Twitter, Instagram, YouTube, Tumblr e de blogs para contestar a misoginia e outros exemplos de desigualdade de gênero (Chamberlain, 2017; Cochrane, 2014; Maclaran, 2015; Risman, 2017). Percebe-se que o tema Gênero passa a ascender dentro do presente estudo de Empreendedorismo Rural, dois anos após essa emergência da "quarta onda feminista". A influência dos movimentos sociais de mulheres é notável também dentro de outras produções científicas, pelo crescente número de documentos relacionados ao tema de Gênero em diversas áreas do conhecimento. Incluindo os estudos de empreendedorismo de forma geral, as pesquisas que têm como âmbito central o meio rural.

Além da variável temporal (anos), também foram analisados os setores de negócios. Foram identificados, por meio da leitura, 77 setores distintos nos documentos selecionados sobre Empreendedorismo Rural. Desses, foram escolhidos os dez setores que apresentaram maior frequência, para que fosse possível dimensionar a distribuição dos sete temas principais dentro destes conjuntos de dados, fazendo assim uma relação entre temas e setores (Figura 6).

Figura 6 - Frequência dos sete temas principais dentro de cada um dos dez setores de negócios que mais ocorreram nos documentos referentes ao Empreendedorismo rural, nas bases de dados SciVerse Scopus $\AA^{\text {e }}$ Web of Science ${ }^{\circledR}$ no período de janeiro de 1999 - junho de 2019

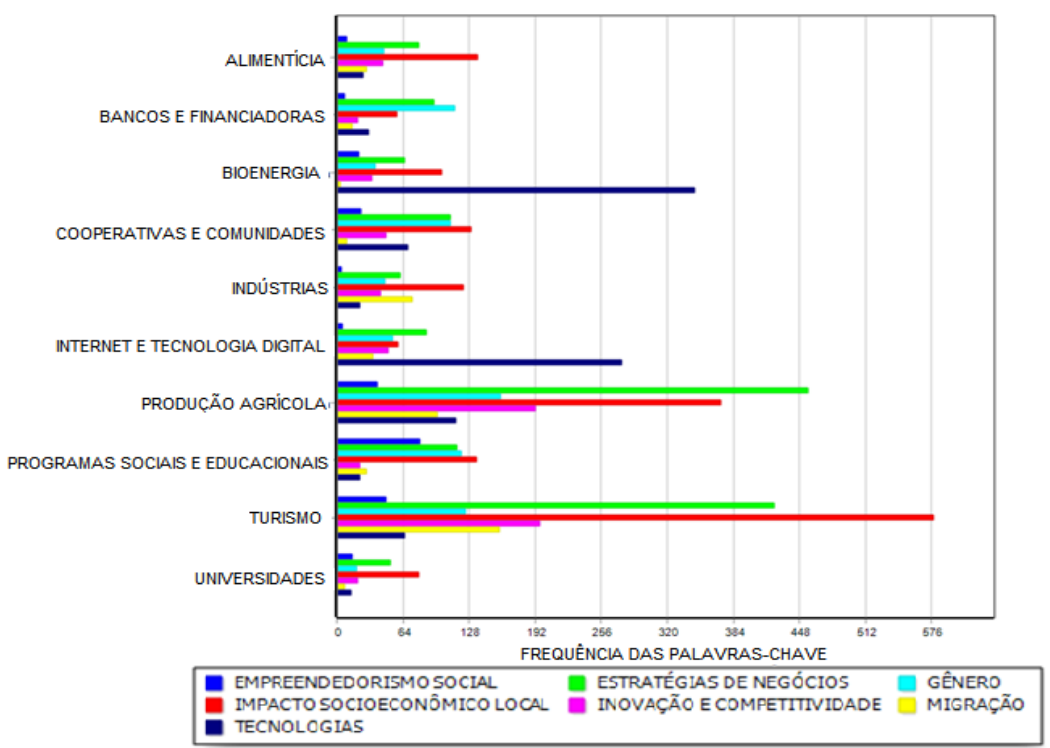

Fonte: Elaborado pelos autores (2019).

Os setores alimentício, cooperativas e comunidades, indústrias, programas sociais e educacionais, turismo e universidades apresentaram como principal tema o impacto socioeconômico local. Verificou-se, assim, uma relação mais estreita destes setores com a área social. Já setor de bioenergia e o de internet e tecnologias digitais apresentaram como objeto principal as tecnologias em si.

O setor mais tradicional do meio rural, o de produção agrícola, apresentou como principal tópico o de Estratégias de Negócio. Além disso, foi um dos setores que mais indicou interesse em Inovação e Competitividade, demonstrando que o empreendedorismo agrícola tem um maior interesse no funcionamento dos mercados e empresas.

O setor de Bancos e Financiadoras se difere dos demais por dar uma maior atenção tema de gênero. Foram identificadas diversas pesquisas que analisavam os programas de crédito que têm como intuito incentivar ao empreendedorismo feminino, principalmente em países em desenvolvimento. De acordo com Patil e Kokate (2017), houve um rápido crescimento desses países em desenvolvimento, como China e Índia, porém o progresso 
foi desigual, fazendo com que as mulheres ficassem mais propensas à pobreza e tendo mais dificuldade no acesso ao mercado de trabalho remunerado, à educação e ao direito de propriedade.

Diversos estudos analisam programas de financiamento, como o "Self-Help Group-Bank Linkage Program" do “National Bank for Agriculture and Rural Development" (NABARD) da Índia, como instrumentos para solucionar o problema da desigualdade entre gêneros no momento de empreender. Tais estudos visam o desenvolvimento do empreendedorismo e/ou características empreendedoras que podem ser desenvolvidas pelos grupos de mulheres que receberam o auxílio.

A partir dessa análise foi possível compreender melhor a dinâmica que ocorre em alguns países, por isso também foi verificada a distribuição geográfica dos estudos encontrados. Foi encontrado um total de 140 países diferentes, distribuídos nos cinco continentes África, América, Ásia, Europa e Oceania. Importante destacar que alguns estudos contemplavam mais de uma região e outros não abordavam regiões específicas. Desta forma, os países que obtiveram maior número de pesquisas foram: Índia (225), Estados Unidos (203), China (175), Espanha (86), África do Sul (74), Inglaterra (54), Itália (53), Austrália (52), Suécia (52), Brasil (52), Bangladesh (48) e Finlândia (48).

Após, esses doze países selecionados, que apresentaram maior frequência no conjunto de documentos sobre Empreendedorismo Rural, foram relacionados aos os sete principais temas a partir da Mineração de Textos (Figura 7).

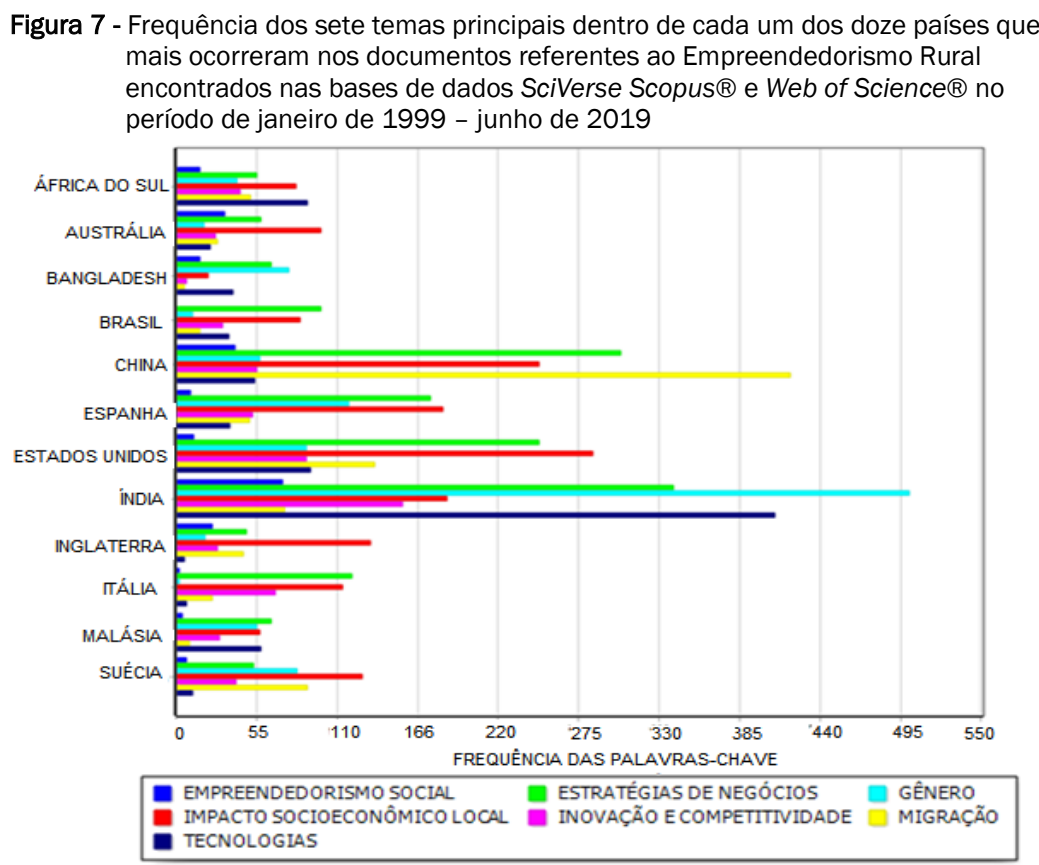

Fonte: Elaborado pelos autores (2019).

Percebe-se que os países desenvolvidos, com um alto Índice de Desenvolvimento Humano (IDH), que aparecem nesta lista apresentaram como tema mais abordado o Impacto Socioeconômico Local. Segundo Human Development Report Office (2018), os países Austrália (IDH: 0.939), Suécia (IDH: 0.933), Estados Unidos (IDH: 0.924), Inglaterra ( $\mathrm{DH}: 0.922$ ) e Espanha (IDH: 0.891), estão ranqueados respectivamente em $3^{\circ}, 7^{\circ}, 13^{\circ}, 14^{\circ} \mathrm{e}$ $26^{\circ}$ na lista dos países mais desenvolvidos do mundialmente. Demostrando que as produções científicas, relacionadas ao empreendedorismo no meio rural, nessas regiões têm como interesse as transformações sociais e econômicas.

O Brasil, a Malásia e a Itália são lugares que abordam mais as Estratégias de Negócios. As pesquisas realizadas nesses países estão mais próximas às linhas dos livros de empreendedorismo citados anteriormente, ou seja, mais voltadas ao funcionamento dos mercados e empresas e menos focadas nos impactos causados à sociedade.

O tema de Tecnologia foi o mais abordado em estudos na África do Sul. Segundo Todd e Javalgi (2007), os avanços na tecnologia da informação e as melhorias na infraestrutura de comunicação aumentam as oportunidades das Pequenas e Médias Empresas (PME) de participarem dos mercados globais nos países em desenvolvimento. Abor e Quartey (2010) indicam que na República da África do Sul cerca de 91\% das entidades formais de negócios são PME, e que essas contribuem entre 52 a $57 \%$ para o PIB e fornecem cerca de $61 \%$ dos empregos. 
O desenvolvimento dessas empresas, no entanto, é amplamente restringido por fatores como a falta de acesso à tecnologia apropriada, acesso limitado aos mercados internacionais e a existência de leis, regulamentos e regras que impedem o desenvolvimento do setor (Lekhanya, 2014). Desta forma, o assunto sobre tecnologia nesta região acabe tornando-se objeto de interesse de diversas pesquisas.

A Índia também aborda de forma expressiva o tema das Tecnologias, até porque, conforme o relatório da Associação Nacional de Empresas de Software e Serviços, (2017) ela foi classificada como o terceiro maior ecossistema de startups do mundo e a segunda nação mais conectada a internet no ranking global. Obviamente, é necessário pensar nestes dados levando em consideração a alta densidade populacional deste país, estimada em 1,37 bilhões de pessoas no ano de 2019, perdendo apenas para a China (World Population Review Privacy, 2017). Entretanto, diferentemente da África do Sul, o tema de maior interesse da Índia não foi o da Tecnologia e sim o de Gênero. Junto de Bangladesh, país geograficamente e culturalmente próximo.

Segundo a Thomson Reuters Foundation (2017) uma pesquisa realizada por 550 especialistas em questões das mulheres, constatou que a Índia é o pior país para as mulheres viverem, sendo o mais perigoso. E de acordo com Bortamuly, Goswami e Hazarika (2015), embora as mulheres constituam cerca de metade da população total do país, a sua participação nas atividades econômicas formais é baixa. Logo, pesquisas sobre gênero nesta região são importantes. Tais estudos demonstram uma relação entre o empreendedorismo e a busca por condições sociais e econômicas melhores para as mulheres.

Outro problema social encontrado foi o da Migração, tema que apresentou destaque na China. De acordo com Ning e Qi (2017), diversos trabalhadores rurais migraram para trabalhar em áreas urbanas desde o início da reforma econômica da China no final da década de 1970. A proporção de residentes da área urbana passou de 17,92\% em 1978 para 49,86\% em 2010 (Qin \& Zhang, 2014). Esse número é ainda maior se for levado em conta os trabalhadores que residem no meio rural, mas trabalham nos centros urbanos, situação essa que ocorre devido a barreiras e restrições institucionais, como o sistema de registro de residentes chamado Hukou. Nesse sistema, a maioria desses migrantes não é permitida a morar em cidades permanentemente sem converter seu Hukou rural em urbano.

Assim, com a expansão dos migrantes rurais-urbanos no país, aumentaram também os autônomos e, diante a isto, emergiu uma variedade de políticas aplicadas para incentivar a inovação e o empreendedorismo visando esses trabalhadores. Devido a tal cenário, aumentaram as produções científicas sobre o tema Migração na China. Desta forma além dos países de estudo, também foram analisadas as áreas de conhecimento dos documentos e distribuição dos temas em questão dentro delas (Figura 8).

Figura 8 - Frequência dos sete temas principais dentro de cada uma das treze áreas do conhecimento que ocorreram nos documentos sobre Empreendedorismo rural encontrados nas bases de dados SciVerse Scopus $\AA^{\circledR}$ e Web of Science ${ }^{\circledR}$ no período de 1999 - junho de 2019

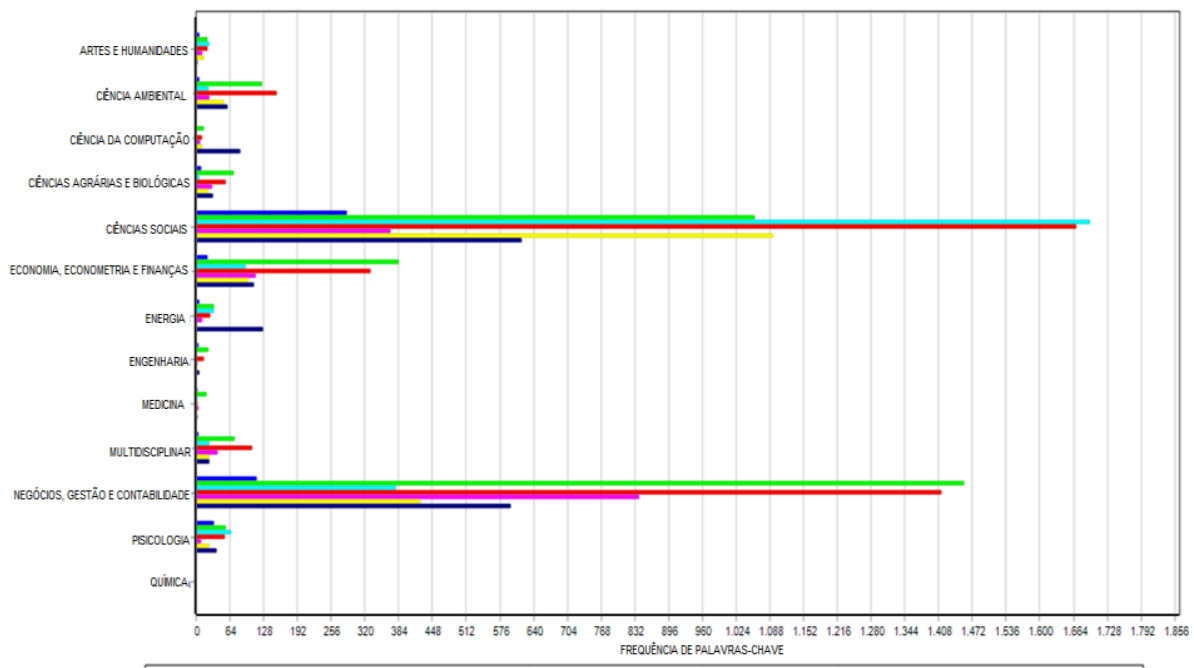

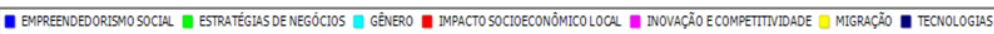

Fonte: Elaborado pelos autores (2019).

A concentração dos estudos em Empreendedorismo Rural ficou nas áreas de Ciências Sociais e Negócios, com destaque para o tema Impacto Socioeconômico Local, e de Gestão e Contabilidade, onde a temática Estratégias de Negócios se sobressaiu. 
As Ciências Sociais compreendem o conjunto de saberes relativos às áreas da Antropologia, da Sociologia e da Ciência Política e diferem das Ciências Físicas ou Naturais na medida em que lidam com as pessoas e seu comportamento social e que as pessoas são menos previsíveis que os fenômenos não humanos (Veal, 2006).

Essas mesmas características podem ser encontradas nos estudos da área de Negócios, Gestão e Contabilidade, por esta estar inserida na Administração, que é definida pelo Conselho Nacional de Desenvolvimento Científico e Tecnológico (2019) como uma Ciência Social Aplicada.

Sendo assim, as áreas de conhecimento das pesquisas sobre Empreendedorismo Rural são em sua maioria ligadas ao comportamento do homem e da sociedade e, por sua complexidade, menos precisas quando comparadas às áreas das Ciências Exatas, embora sejam relevantes para a sociedade.

\subsection{Empreendedorismo Rural e o Turismo}

Ao analisar os setores, o turismo destacou-se dentro dos estudos sobre empreendedorismo rural (Figura 9), superando até mesmo atividades mais tradicionais do meio rural como a produção agropecuária. De acordo com Kageyama (2004), modificações no campo passaram a dar espaço para o desenvolvimento de atividades não agrícolas nas propriedades rurais. Ou seja, atividades como o turismo rural estão tendo uma maior relevância no rural.

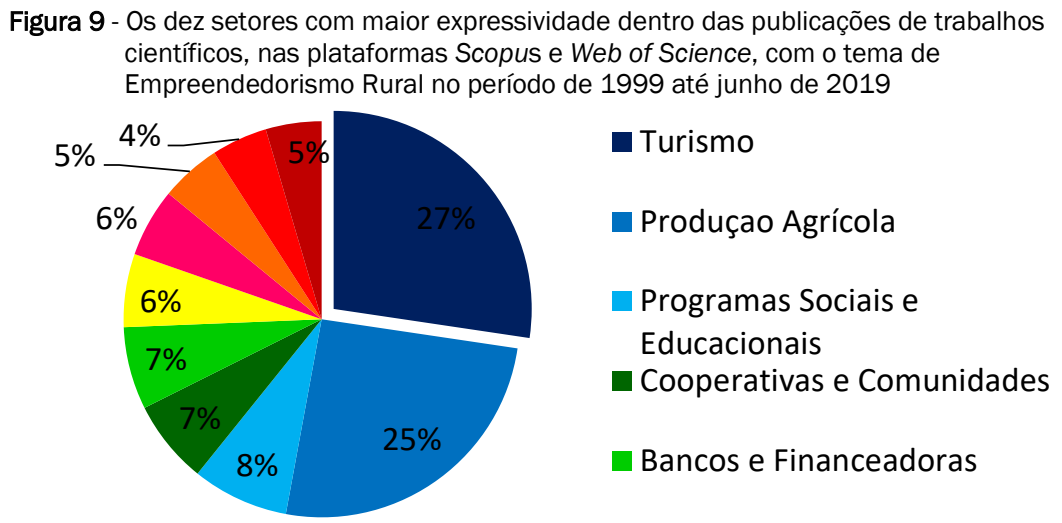

Fonte: Elaborado pelos autores (2019).

Deste modo, foram realizadas análises dos 288 documentos relacionados ao setor de turismo, os quais foram encontrados na primeira busca sobre Empreendedorismo Rural. Assim foi feito um estudo semelhante ao anterior com o conjunto sobre o turismo rural no empreendedorismo rural a respeito das dimensões dos sete temas nestes arquivos (Figura 10).

Figura 10 - Frequência dos sete temas principais que ocorreu no conjunto de documentos relacionado ao setor de Turismo inserido dentro dos dados sobre Empreendedorismo Rural encontrados nas bases de dados SciVerse Scopus ${ }^{\circledR}$ e Web of Science ${ }^{\circledR}$ no período de 1999 - junho de 2019

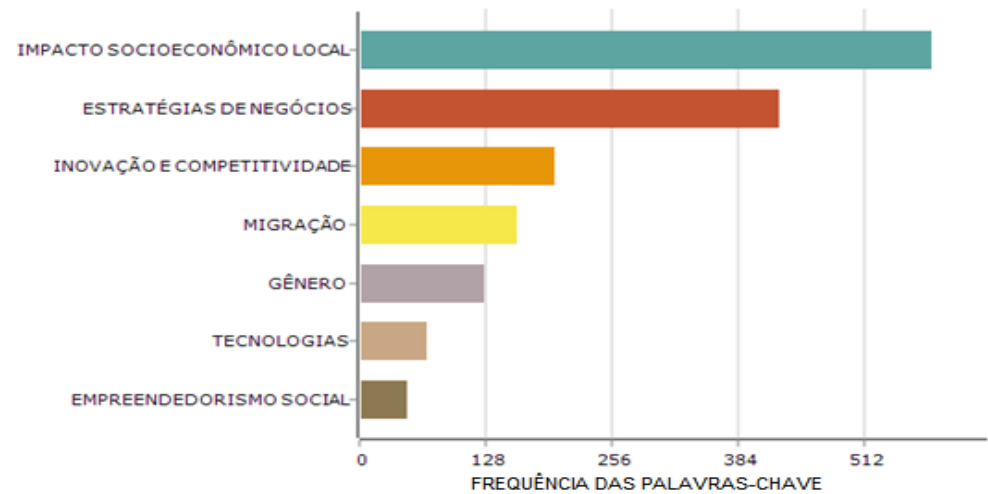

Fonte: Elaborado pelos autores (2019).

O Impacto Socioeconômico Local também é o tema em maior destaque dentro do conjunto sobre turismo e empreendedorismo rural. A maioria são estudos de caso que analisam as transformações ocorridas a partir da 
inserção das atividades turísticas em uma localidade rural como, por exemplo, as transformações a partir da criação de empregos e renda aos moradores da região, e, assim, o desenvolvimento socioeconômico da comunidade (Adefila \& Yusuf, 2012; Mitchell \& Shannon, 2018), o possível empoderamento destes residentes (Ajagunna, Pinnock, \& Kerr, 2014; Jaafar, Dahalan, \& Asma Mohd Rosdi, 2014; Pradono, Faisal, Adriani, Rikeu, \& Fajriasanti, 2016), a melhoria na sua qualidade de vida (Boukas, 2019), a diminuição da pobreza local (Mthembu \& Mutambara, 2018), o impacto causado ao ambiente (Varela \& Gil, 2011; Vargas-Vargas \& Mondéjar-Jiméne, 2010), as modificações trazidas pela infraestrutura implantada (Currie \& Falconer, 2012), entre outros impactos.

Essas análises são importantes, pois, conforme Varela e Gil (2011), é necessário investir em modelos de turismo que tenham um baixo impacto ambiental, mas que proporcionem empregos, renda e serviços fundamentais que melhorem a qualidade de vida da comunidade local.

Percebe-se que após a temática do Impacto Socioeconômico Local estão os tópicos sobre Estratégias de Negócios e sobre Inovação e Competitividade, ambos relacionados à atividade do turismo em si. Tais tópicos analisavam, por exemplo, variáveis do regime financeiro (Sgroi, Donia, \& Mineo, 2018) e do marketing (Carlisle, Kunc, Jones, \& Tiffin, 2013), bem como sobre gestão e a parte operacional (Matilainen \& Lähdesmäki, 2014), entre outros fatores que contribuem diretamente no desenvolvimento da atividade.

Além dessa distribuição dos sete temas principais, foram analisadas suas evoluções através dos anos (Figura 11).

Figura 11 - Evolução dos sete temas principais que ocorreu no conjunto de documentos relacionado ao setor de Turismo inserido dentro dos dados sobre Empreendedorismo Rural encontrados nas bases de dados SciVerse Scopus ${ }^{\circledR}$ e Web of Science ${ }^{\circledR}$ no período de 1999-2018

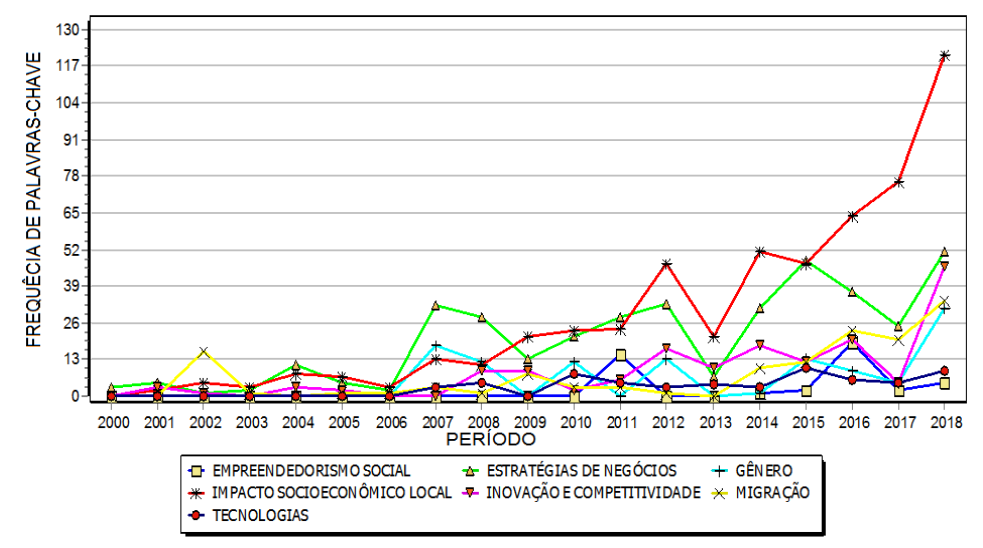

Fonte: Elaborado pelos autores (2019).

O tema de Impacto Socioeconômico Local apresentou um crescimento constante, principalmente nos últimos anos. Ao comparar com a evolução sobre o Empreendedorismo Rural geral, realizada anteriormente, é possível notar que no conjunto de dados referentes ao setor de turismo ocorre um destaque ainda maior para este tema de impacto no cenário recente da produção científica.

De acordo com Zai e Sahr (2019), a identificação dos impactos do turismo faz parte do seu sistema de monitoria e avaliação, uma vez que podem ser positivos ou negativos. Assim, é fundamental que os empreendedores do ramo turístico conheçam estes elementos, para uma gestão mais adequada da atividade.

Além disso, é importante observar o expressivo número de documentos produzidos no ano de 2018, evidenciando um pico de interesse e demonstrando que o Empreendedorismo Rural no setor de Turismo e seus possíveis Impactos Socioeconômicos Locais têm relevância nos tempos atuais. Ainda, o aumento no número de publicações neste setor pode ser reflexo do crescimento mundial do Turismo Rural.

Durante a Conferência de Ministros da Agricultura das Américas de 2019, o Instituto Interamericano de Cooperação para a Agricultura (IICA) assinou um acordo com a Organização Mundial de Turismo das Nações Unidas (OMT) para apoiar a assistência nas áreas de agroturismo e turismo rural nas Américas. Indicou, inclusive, o ano de 2020 como o Ano Internacional do Agroturismo e Turismo Rural, com o intuito de implementar projetos para promover o desenvolvimento de capacidades em áreas como posicionamento e marca de destino no turismo rural, desenvolvimento e diversificação de produtos e habilidades digitais, com assistência financeira de agências internacionais (The Inter-American Institute for Cooperation on Agriculture, 2019). 
Em Londres, os líderes de turismo dos setores público e privado se reuniram no World Travel Market (WTM) a fim de discutir sobre o papel do turismo no desenvolvimento rural. 0 evento reuniu 75 ministros e vice-ministros de turismo, membros da mídia global e profissionais sêniores do setor de viagens para as discussões focadas na inovação e tecnologia do turismo e seu lugar no empoderamento das comunidades rurais (Daily travel \& tourism news, 2019). Na abertura deste evento, Zurab Pololikashvili, político e diplomata da Geórgia e Secretário Geral da Organização Mundial de Turismo, declarou:

Globalmente, a pobreza é predominantemente rural. Isso significa que, se o turismo sério é um fator de crescimento e desenvolvimento, precisamos olhar para fora de nossas cidades: precisamos trabalhar juntos para ajudar até a menor comunidade a aproveitar os muitos e variados benefícios que o turismo pode trazer" (World Tourism Organization, 2019, tradução livre).

E em recente Assembleia Geral, a OMT anunciou "Desenvolvimento Rural e Turismo" como tema do Dia Mundial do Turismo do ano de 2020, comprovando que o Turismo e o Meio Rural veem chamando atenção de órgãos e lideres internacionais. 0 tema Impacto Socioeconômico Local aparece em destaque, não apenas na produção científica, mas também nos principais eventos, audiências e diversas reuniões referentes ao turismo atualmente.

Além do estudo desta distribuição temporal, também foi analisada a distribuição geográfica destas pesquisas. Conforme apresentado anteriormente, os países foram identificados a partir de uma leitura prévia do conjunto de documentos referentes ao setor de turismo dentro do Empreendedorismo Rural. Foi encontrado um total de 91 países diferentes. As regiões com maior número de pesquisas foram: Espanha (24), Estados Unidos (19), Suécia (18), China (17), Itália (13), Romênia (11), Finlândia (10), Portugal (8), África do Sul (8), Inglaterra (8), Malásia(8), Nova Zelândia (7), Canadá (7), Brasil (7) e Grécia (7).

Assim foram analisados os sete temas dentro destes quinze países mais frequentes dentro do conjunto de documentos sobre Empreendedorismo Rural relacionado ao setor do turismo (Figura 12). Optou-se por selecionar quinze países e não doze, como foi feito anteriormente na análise referente ao conjunto total de dados, para incluir o Brasil e por haver uma quantidade expressiva de países com o mesmo número de estudos.

Figura 12 - Frequência dos sete temas principais dentro de cada um dos quinze países que mais ocorreram no conjunto de documentos relacionado ao setor de Turismo inserido dentro dos dados sobre Empreendedorismo Rural encontrados nas bases de dados SciVerse Scopus ${ }^{\circledR}$ e Web of Science ${ }^{\circledR}$ no período de 1999 junho de 2019

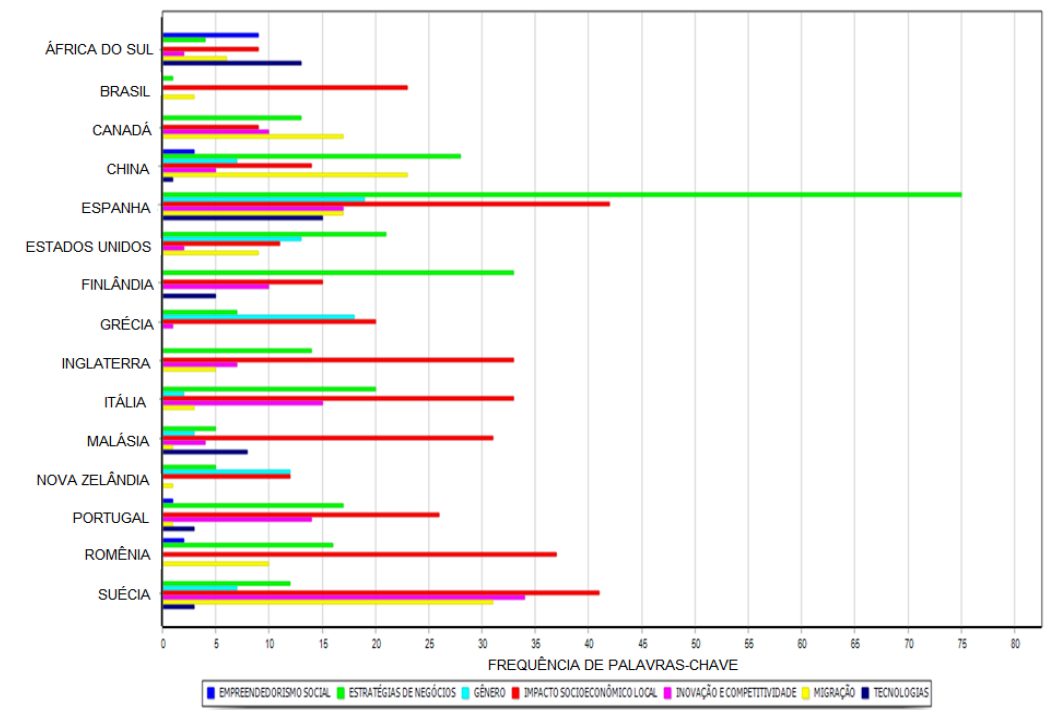

Fonte: Elaborado pelos autores (2019).

Ao comparar com o gráfico que analisou os países com maior frequência em relação ao conjunto total de dados sobre empreendedorismo, na Figura 12, com este que apresenta as regiões de maior frequência apenas dos dados ligados ao setor de turismo, é possível notar algumas diferenças, como a saída de países como a Índia, Bangladesh e Austrália, que apareciam no primeiro gráfico, demonstrando como estes locais não abordam tanto o setor do turismo relacionado ao empreendedorismo rural.

Ressalta-se que a Índia, a região de maior destaque dentro dos dados de empreendedorismo rural, não obteve tanta frequência quando o assunto incluía o setor do turismo. 0 país em questão apresentou anteriormente alta preocupação com a questão de gênero, mas os estudos não buscam no turismo uma possível solução para este tipo de problema. 
Enquanto na análise dos dados relacionados ao turismo foram inseridos países como o Canadá, Grécia, Malásia, Nova Zelândia, Portugal e Romênia. Na segunda análise, referente ao turismo, foi apresentada uma maior quantidade de países, visto alguns desses terem o mesmo número de produções, ficando empatados nas primeiras posições.

O maior destaque percebido nesta análise é o tema Estratégias de Negócios. A Espanha é o país com maior produção científica sobre Empreendedorismo Rural ligado ao turismo. Esta região tem como objeto de estudo os aspectos e estratégias dentro do setor turístico. Talvez tal fato seja resultado da Espanha ser considerada um dos destinos turísticos mais representativos e significativos do mundo.

Na Espanha, os negócios de turismo, incluindo empresas menores, têm uma experiência considerável na realização de atividades de gestão, por exemplo, no planejamento de marketing. Nesse contexto, o setor de turismo rural pode ser considerado também um dos mais representativos (Polo-peña, Frías-jamilena, \& Rodríguez-molina, 2012).

De fato, as estratégias de desenvolvimento do turismo no meio rural oferecem soluções potenciais para problemas nas áreas rurais. Por exemplo, a criação de empregos associada ao desenvolvimento de negócios turísticos traz um aumento de renda para a criação de novos mercados agrícolas, aumento da oportunidade de promover o artesanato local e outros bens que possam ampliar o mercado regional, ativando a competitividade entre os empreendedores locais (Fleischer \& Tchetchik, 2005; Frochot, 2005; Getz \& Carlsen, 2005). 0 crescimento do turismo nas áreas rurais pode ser uma estratégia para desencadear um papel significativo no desempenho de “criação de valor" e "valor agregado" na economia local (Phelan, 2014).

O assunto de Estratégias também apareceu como destaque para países como a China, Estados Unidos e Finlândia. Demonstrando que tais lugares abordam as estratégias do turismo como principal fator. Aqui também cabe lembrar como a China obteve destaque no tema de Migração anteriormente, embora nos estudos referentes ao turismo o tema de Estratégias ultrapasse o de Migração. O Canadá, por sua vez, faz uma maior relação com esse tema de Migração, ao incluir o turismo no Empreendedorismo Rural.

Entretanto, a maioria dos países como Brasil, Grécia, Inglaterra, Itália, Malásia, Portugal, Romênia e Suécia, segue abordando mais os Impactos Socioeconômicos Locais ligados ao Empreendedorismo Rural com o setor de Turismo. Na produção científica de revistas acadêmicas brasileiras, por exemplo, é fácil encontrar estudos que apontam o turismo rural como forma de impacto positivo na economia local (Campanhola \& Silva, 2000; Motta, 2013; Silva \& Fran-, 2010; Vasconcelos, 2011).

Além dos países de estudo, também foram analisadas as áreas de conhecimento destes documentos referentes ao turismo e a distribuição dos temas em questão dentro delas (Figura 13).

Figura 13 - Frequência dos sete temas principais dentro de cada uma das oito áreas de conhecimento que ocorreram no conjunto de documentos relacionado ao setor de Turismo inserido dentro dos dados sobre Empreendedorismo Rural encontrados nas bases de dados SciVerse Scopus ${ }^{\circledR}$ e Web of Science ${ }^{\circledR}$ no período de janeiro de 1999 - junho de 2019

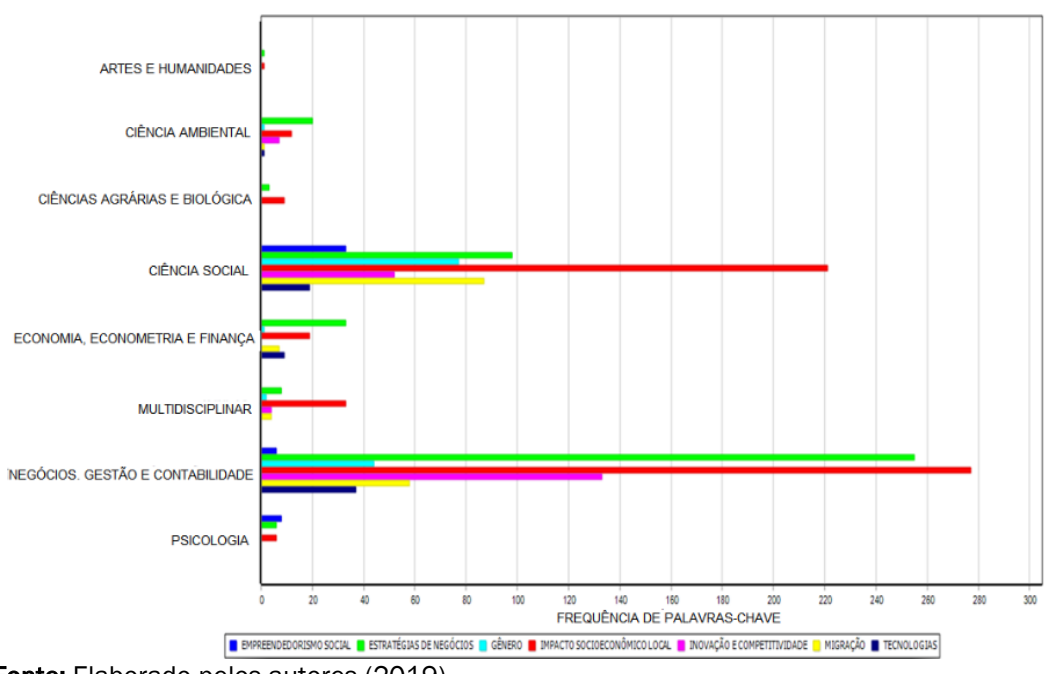

Fonte: Elaborado pelos autores (2019).

Notou-se uma semelhança à distribuição anterior, repetindo uma concentração nas áreas de Ciências Sociais e Negócios, Gestão e Contabilidade. Desta vez, contudo, houve um destaque do tema Impacto Socioeconômico Local 
em ambas as áreas, demonstrando que quando os dados de Empreendedorismo Rural são ligados ao setor de Turismo, este tema tem um número ainda maior de produções científicas, chamando mais atenção para as transformações da sociedade local e sua economia.

A realidade da pesquisa brasileira em turismo segue uma tendência semelhante. Segundo Nonato (2010) o campo de estudo do Turismo no Brasil dialoga com as áreas como Sociologia, Antropologia, Geografia, Arquitetura e Urbanismo, Administração, Economia, Direito dentre outros.

\section{CONSIDERAÇÕES FINAIS}

A história do empreendedorismo teve suas raízes ligadas ao meio rural, devido seu conceito emergir em uma época em que o setor agrícola obtinha uma supremacia incontestável e praticamente exclusiva, quando se falavam em negócios e mercado. Porém, os estudos e entendimentos sobre empreendedorismo passou por alguns anos a se distanciarem do meio rural, e se concentrar em setores mais urbanos. Recentemente os estudos do empreendedorismo no contexto rural passaram a se desenvolver novamente.

O Empreendedorismo Rural contém características particulares, como uma forte expansão do mercado turístico. Neste sentido, o presente trabalho teve como objetivo abordar a evolução da produção científica sobre esse Empreendedorismo Rural, e a sua ligação ao setor de Turismo, para que assim fosse possível aprofundar o conhecimento sobre alguns elementos dentro destes estudos.

Deste modo, primeiramente foram identificadas as informações básicas sobre essa produção. Assim se obteve as principais temáticas dos estudos na área, as quais foram: Empreendedorismo Social, Estratégias de Negócio, Gênero, Impacto Socioeconômico Local, Inovação e Competitividade, Migração e Tecnologias.

Na segunda parte do trabalho, foram feitas as análises dos estudos sobre Empreendedorismo Rural, e do conjunto que continha ligação com o setor do turismo, por sobressair-se em relação aos outros. Foi possível notar, por exemplo, o crescimento do número de artigos e revisões e, principalmente, da preocupação com os Impactos Socioeconômicos Locais.

Em ambas as análises, tanto a do conjunto geral sobre empreendedorismo rural quanto os que eram apenas relativos ao turismo, a dimensão do Impacto Socioeconômico Local esteve presente. Demonstrou-se que dentro da produção científica esse é um dos maiores interesses, visando às transformações e ao desenvolvimento que o empreendedorismo poderia levar ou não aos locais.

Outros aspectos foram percebidos ao analisar a distribuição geográfica destes estudos. A Índia, por exemplo, é um país que costuma ser estudado quando se aborda o Empreendedorismo Rural e, nesta região, o tema de maior relevância é o de Gênero, em consequência dos problemas sociais enfrentados no local. Entretanto, nota-se que o setor do turismo não é expressivo nestas pesquisas, ou seja, a Índia não considera o empreendedorismo com o turismo nas áreas rurais como uma solução para os problemas de gênero, visto que, de acordo com o estudo realizado, a região não vem apresentando investimentos na atividade turística.

Enquanto a Espanha demonstra uma forte ligação com o empreendedorismo relacionado ao turismo no meio rural, o país não aparece entre os mais frequentes no conjunto geral, mas passa para o primeiro lugar quando se analisa somente o conjunto que tem conexão com setor de turismo. Ou seja, os estudos evidenciam o desenvolvimento do turismo no meio rural nesta região, a qual também demonstra ter um maior interesse em Estratégias de Negócio.

A partir das análises desses estudos em cada país é possível compreender melhor como ocorre a dinâmica do empreendedorismo rural e do setor de turismo nas diferentes regiões, as quais contém contextos e características distintas. Demonstrando que o empreendedorismo pode ser visto de diferentes pontos de vista, sendo colocado em posições diferentes dependendo do local.

Ao analisar as áreas do conhecimento, evidencia-se que os estudos seguem concentrados em Ciências Sociais e Negócios, Gestão e Contabilidade. Tal cenário é normal devido ao Empreendedorismo estar diretamente interligado a estas áreas, entretanto também traz a necessidade de expansão destes estudos, pois é um tópico amplo, que passou a ser pesquisado a partir de visões distintas, sendo abordado nas mais diferentes disciplinas na tentativa de compreender e explicar o empreendedorismo e os empreendedores.

Desta forma, a contribuição teórica do presente trabalho foi apresentar uma análise que tornasse possível melhor compreender a evolução das pesquisas sobre Empreendedorismo Rural e a sua ligação com o setor de Turismo. Foram analisadas as características dos países e setores que foram objetos das pesquisas em questão, e 
observando que existe ainda espaço pra expandir as pesquisas em diferentes áreas do conhecimento, principalmente no Brasil, já que configurou apenas com 52 artigos em âmbito internacional, além de notar a necessidade de expandir o tema com abordagens de outras áreas do conhecimento.

Dentre as limitações na pesquisa, encontra-se a utilização apenas de artigos e revisões de duas bases de dados cientifica. Seria interessante ampliar esse conjunto de dados, incluindo outras formas de documentos, que poderiam ter diferentes origens como, por exemplo, dados não científicos, encontrados nas mídias.

Outra limitação foi na elaboração dos dicionários, por haver muitas palavras semelhantes nas listas de frequências utilizadas para sua confecção, foram excluídas diversas palavras, e foi utilizado um número pequeno de termos no presente trabalho. Sugere-se a inclusão de uma quantidade maior de termos, porém esses com as devidas regras para manter a precisão desta pesquisa, assim sendo possível utiliza-los em diversos conjuntos de dados. Além disso, há a possibilidade de incluir novos temas, ou seja, encontrar tópicos que foram deixados de fora desta análise, porém que são relevantes ao Empreendedorismo Rural e ao Turismo. Também que se realize esta pesquisa em base de dados nacionais, para que se faça uma análise da realidade da produção científica brasileira.

Por fim, este trabalho apresentou como ponto forte a extração de conhecimento de uma quantidade expressiva de dados e informações sobre Empreendedorismo Rural e o Empreendedorismo Rural no Turismo, permitindo uma compreensão mais aprofundada sobre estas questões e seus aspectos através dos últimos vinte anos e demonstrando a sua importância dentro da ciência.

Sendo assim, a contribuição da ciência para a sociedade é inquestionável, na medida em que ela possibilita avanços nos mais diversos campos, desde as áreas de ciências exatas até as ciências humanas, todas com intuito de melhorar a qualidade de vida humana e do meio ambiente. Produzir conhecimento é importante e saber o que fazer com esse acúmulo de conhecimento é essencial.

\section{AGRADECIMENTOS}

Os autores agradecem aos colaboradores, professores e colegas do programa de Pós-Graduação em Agronegócio do CEPAN / UFRGS pelo apoio na condução deste trabalho. Agradecem também ao Conselho Científico e Tecnológico Nacional (CNPQ) pela assistência financeira durante este estudo.

\section{REFERÊNCIAS}

Abor, J., \& Quartey, P. (2010). Issues in SME development in Ghana and South Africa. IIternational Research Journal of Finance and Economics, 39, p. 1450-2887.

Acs, J. Z., \& Audretsch, D. B. (2005). Handbook Of Entrepreneurship Research An Interdisciplinary Survey And Introduction. Kluwer Academic Publishers.

Adefila, J. O., \& Yusuf, R. O. (2012). Agricultural tourism for socio-economic development in Esie-Irepodun area, Kwara State. European Journal of Social Sciences, 28(3), p. 326-334.

Ajagunna, I., Pinnock, F., \& Kerr, R. (2014). Wilderness tourism - alleviating poverty through empowering local people. Worldwide Hospitality and Tourism Themes, 6(3), 229-243. https://doi.org/10.1108/whatt-032014-0016

Alabi, D. L., \& Famakinwa, M. (2019). Bridging Male-Female Gaps in Rural Entrepreneurship Capability Development in Osun State , Nigeria. (January). https://doi.org/10.4314/jae.v23i1.7

Associação Nacional de Empresas de Software e Serviços. (2017). Relatório da NASSCOM 2017. Recuperado set. 9, 2019, de https://www.nasscom.in/

Audretsch, D. B., Lehmann, M. C., \& Keilbach, E. E. (2006). Entrepreneurship and Economic Growth. Oxford: Oxford University Press.

Baumol, W. J. (1996). Entrepreneurship: Productive, Unproductive, and Destructive. Journal of Business Venturing, 11(3), p. 3-22. https://doi.org/doi:10.1016/0883-9026(94)00014-X.

Bortamuly, A. B., Goswami, K., \& Hazarika, B. (2014). Do different determinants affect differently across gender and location in handloom entrepreneurship development? Journal of Small Business \& Entrepreneurship, 6331(March 2016), p. 427-449. https://doi.org/10.1080/08276331.2015.1088298

Boukas, N. (2019). Rural tourism and residents' well-being in Cyprus: towards a conceptualised framework of the appreciation of rural tourism for islands' sustainable development and competitiveness. International Journal of Tourism Anthropology, 7(1), p. 60-86. https://doi.org/10.1504/ijta.2019.098105

Burger-helmchen, T. (2012). Creativity And Innovative Business Edited by Thierry Burger-Helmchen. InTech. 
Campanhola, C., \& Silva, G. J. (2000). O agroturismocomo nova fonte de renda para o pequeno agricultor brasileiro. In Turismo Rural Ecologia, lazer e desenvolvimento. EDUSC.

Carlisle, S., Kunc, M., Jones, E., \& Tiffin, S. (2013). Supporting innovation for tourism development through multistakeholder approaches: Experiences from Africa. Tourism Management, 35, p. 59-69. https://doi.org/10.1016/j.tourman.2012.05.010

Chamberlain, P. (2017). The Feminist Fourth Wave: Affective Temporality. Palgrave Macmillan.

Cochrane, K. (2014). All the Rebel Women: The rise of the fourth wave of feminism. Guardian Books.

Conselho Nacional de Desenvolvimento Científico e Tecnológico. (2019). Áreas do Conhecimento - Ciências Sociais Aplicadas do CNPQ. Recuperado nov. 22, 2019, de http://lattes.cnpq.br/web/dgp/ciencias-sociaisaplicadas

Crawford, E. (1999). The Women's Suffrage Movement: A Reference Guide 1866- 1928. UCL Press.

Currie, C., \& Falconer, P. (2012). Maintaining sustainable island destinations in Scotland: The role of the transporttourism relationship. Journal of Destination Marketing \& Management, 3(3), p. 162-172. https://doi.org/10.1016/i.jdmm.2013.10.005

Daily travel \& tourism news. (2019). Innovation and rural development takes center stage for Ministers' Summit at WTM. Recuperado nov. 26, 2019, de https://www.traveldailynews.com/post/innovation-and-ruraldevelopment-takes-center-stage-for-ministers-summit-at-wtm

Dias, C. S. L., Rodrigues, R. G., \& Ferreira, J. J. (2019). Agricultural entrepreneurship: Going back to the basics. Journal of Rural Studies, 70(March), 125-138. https://doi.org/10.1016/j.jrurstud.2019.06.001

Fleischer, A., \& Tchetchik, A. (2005). Does rural tourism benefit from agriculture? Tourism Management, 26, p. 493 -501. https://doi.org/10.1016/i.tourman.2003.10.003

Friedan, B. (1963). The feminine mystique. New York, NY: W. W. Norton. W. Norton.

Frochot, I. (2005). A benefit segmentation of tourist in rural areas: A scottish perspective. Tourism Management, p. 335-346. https://doi.org/10.1016/j.tourman.2003.11.016

Getz, D., \& Carlsen, J. (2005). Family business in tourism: State of the art. Annals of Tourism Research, 32(1), p. 237-258. https://doi.org/10.1016/j.annals.2004.07.006

Gillis, S., Howie, G., \& Munford, R. (2004). Third-wave feminism: a critical exploration. New York: Palgrave Macmillan.

Hippner, H., \& Rentzmann, R. (2006). Text Mining. Informatik Spektrum, 29(4), p. $287-288$. https://doi.org/10.1007/s00287-006-0091-y

Honig, B. (2016). Institutionalization of the Field and its Impact on Both the Ethics and the Quality of Entrepreneurship Research in the Coming Decades. In A. F. and P. (Ed.), Rethinking Entrepreneurship (pp. 123-136). New York: Routledge.

Human Development Report Office. (2018). Human Development Indices and Indicators: 2018 Statistical Update. Recuperado nov. 22, 2019, from HDRO website: http://hdr.undp.org/sites/default/files/hdi table.pdf

Jaafar, M., Dahalan, N., \& Asma Mohd Rosdi, S. (2014). Local Community Entrepreneurship: A Case Study of the Lenggong Valley. Asian Social Science, 10(10). https://doi.org/10.5539/ass.v10n10p226

Kageyama, A. (2004). Desenvolvimento Rural: Conceito E Medida. Cadernos de Ciência \& Tecnologia, 21(3), p. 379-408. http://dx.doi.org/10.35977/0104-1096.cct2004.v21.8702

Lans, T., Verstegen, J., \& Mulder, M. (2011). Analysing, pursuing and networking: Towards a validated three-factor framework for entrepreneurial competence from a small firm perspective. International Small Business Journal, 29(6), p. 695-713. https://doi.org/10.1177/0266242610369737

Lekhanya, L. M. (2014). The Significance of Emerging Technologies in Promoting Internationalization of Rural SMEs in South Africa. Mediterranean Journal of Social Sciences, 5(20), p. 2717-2725. https://doi.org/10.5901/mjss.2014.v5n20p2717

Liang, A. R. (2017). Considering the role of agritourism co-creation from a service-dominant logic perspective.Tourism Management. 61, 2010-2012. https://doi.org/10.1016/j.tourman.2017.02.002

Maclaran, P. (2015). Feminism 's fourth wave : a research agenda for marketing and consumer research. Journal of Marketing Management, 1376(September). https://doi.org/10.1080/0267257X.2015.1076497

Matilainen, A., \& Lähdesmäki, M. (2014). Nature-based tourism in private forests: Stakeholder management balancing the interests of entrepreneurs and forest owners? Journal of Rural Studies, 35, p. 70-79. https://doi.org/10.1016/i.jrurstud.2014.04.007 
Mcelwee, G. (2008). A taxonomy of entrepreneurial farmers. Int J Entrep Small Bus, (June 2008). https://doi.org/10.1504/IJESB.2008.019139

Mitchell, C. J. A., \& Shannon, M. (2018). Exploring cultural heritage tourism in rural Newfoundland through the lens of the evolutionary economic geographer. Journal of Rural Studies, 59, p. 21-34. https://doi.org/10.1016/j.jrurstud.2017.12.020

Motta, E. G. (2013). Turismo no Espaço Rural: as transformações socioambientais no caminho do vinho em São José dos Pinhais/PR. Universidade federal do Paraná.

Mthembu, B., \& Mutambara, E. (2018). Rural Tourism as a Mechanism for Poverty Alleviation in Kwa-Zulu-Natal Province of South Africa: Case of Bergville. Journal of Hospitality, Tourism and Leisure, 7(4), p. 1-22.

Ning, G., \& Qi, W. (2017). Can self-employment activity contribute to ascension to urban citizenship? Evidence from rural-to-urban migrant workers in China. In China Economic Review. https://doi.org/10.1016/j.chieco.2017.07.007

Nonato, R. (2010). Conhecimento Científico Produzido Nos Cursos De Pós-Graduação ( Stricto Sensu ) Em Turismo e Áreas Correlatas no Brasil no Período De 2000 a 2006. Revista Brasileira de Pesquisa em Turismo, p. 64-85. https://doi.org/10.7784/rbtur.v4i2.269

Patil, S., \& Kokate, K. (2017). Identifying factors governing attitude of rural women towards Self- Help Groups using principal component analysis. Journal of Rural Studies, 55, p. 157-167. https://doi.org/10.1016/i.jrurstud.2017.08.003

Phelan, C. (2014). Understanding the farmer: An analysis of the entrepreneurial competencies required for diversification to farm tourism. University of Central Lancashire. University of Central Lancashire.

Polo-peña, A. I., Frías-jamilena, D. M., \& Rodríguez-molina, Á. (2012). Entrepreneurship \& Regional Development : An International Journal Marketing practices in the Spanish rural tourism sector and their contribution to business outcomes. Entrepreneurship \& Regional Development, 24(7), p. 37-41. https://doi.org/10.1080/08985626.2011.617787

Pradono, P., Faisal, B., Adriani, Y., Rikeu, R., \& Fajriasanti, R. (2016). Towards Model of Community Economic Empowerment through Tourism Activities in Bogor Regency, West Java, Indonesia. International Journal of Economics and Financial, 6(6), p. 46-4.

Pyysiäinen, J., Alistair, A., \& McElwee, G. (2006). Developing The Entrepreneurial Skills Of Farmers; Some Myths Explored. Int J Entrep Behav Res, 44(0), 1-21. Pyysiäinen, J., Anderson, A., McElwee, G., \& Vesala, K. (2006). Developing the entrepreneurial skills of farmers: some myths explored. International Journal of $\begin{array}{lllll}\text { Entrepreneurial } \quad \text { Behavior } \quad \text { Research, } & 12(1), & \text { p. } & \text { 21-39. }\end{array}$ https://doi.org/doi:10.1108/13552550610644463

Qin, B., \& Zhang, Y. (2014). Note on Urbanization in China: Urban definitions and census data. China Economic Review, 39, 495-502. Qin, B., \& Zhang, Y. (2014). Note on urbanization in China: Urban definitions and census data. China Economic Review, 30, p. https://doi.org/doi:10.1016/j.chieco.2014.07.008

Risman, B. J. (2017). Where the Millennials Will Take Us: A New Generation Wrestles with the Gender Structure. Oxford: Oxford University Press.

Sgroi, F., Donia, E., \& Mineo, A. M. (2018). Agritourism and local development: A methodology for assessing the role of public contributions in the creation of competitive advantage. Land Use Policy, 77, p. 676-682. https://doi.org/10.1016/j.landusepol.2018.06.021

Sharpley, R., \& Vass, A. (2006). Tourism , farming and diversification : An attitudinal study. Tourism Management, 27(5), p. 1040-1052. https://doi.org/10.1016/j.tourman.2005.10.025

Silva, N. P., \& Fran-, A. C. De. (2010). Turismo rural como fonte de renda das propriedades rurais: um estudo de caso numa pousada rural na Região dos Campos Gerais no Estado do Paraná. Caderno Virtual de Turismo, 10(2), p. 22-37.

Talamini, E., Wuhbben, E. F. M., Padula, A. D., \& Dewes, H. (2013). Scanning the macro-environment for liquid biofuels A comparative analysis from public policies in Brazil, United States and Germany. Journal of Strategy and Management, 6(1), p. 40-60. https://doi.org/10.1108/17554251311296558

The Inter-American Institute for Cooperation on Agriculture. (2019). Events Agroenlace Radio Magazine Videos World Tourism Organization And lica To Strengthen Rural Tourism In Latin America And The Caribbean. Recuperado nov. 26, 2019, de https://www.iica.int/en/press/news/world-tourism-organization-and-iicastrengthen-rural-tourism-latin-america-and-caribbean 
Thomson Reuters Foundation. (2018). Factbox: Which are the world's 10 most dangerous countries for women? Recuperado nov. 22, 2019, de https://www.reuters.com/article/us-women-dangerous-pollfactbox/factbox-which-are-the-worlds-10-most-dangerous-countries-for-women-idUSKBN1JM01Z

Todd, P. R., \& Javalgi, R. G. (2007). Internationalization of SMEs in India Fostering entrepreneurship by leveraging information technology. International journal of emerging markets. TMarkets, International Journal of Emerging, 2(2), 166-180.

Tomazzoni, E. L. (2016). Coletânea de Estudos Turísticos. São Paulo: Universidade de São Paulo - USP.

Varela, C. V., \& Gil, F. M. (2011). Problemas de sostenibilidad del turismo rural en España. Anales de Geografía, 31(1), p. 171-194. https://doi.org/doi:10.5209/rev aguc.2011.v31.n1.8

Vargas-Vargas, M., \& Mondéjar-Jiméne, J. (2010). Environmental Impact And Business Management In Rural Tourism. The Journal of Applied Business Research, 26(3), p. 106. https://doi.org/10.19030/jabr.v26i3.297

Vasconcelos, D. A. (2011). Turismo rural na agricultura familiar: um estudo sobre as possibilidades e limitações no município de Alfredo Vasconcelos, MG. Caderno Virtual de Turismo, 11(3), p. 370-383.

Veal, A. J. (2006). Research Methods ror Leisure And Tourism (3). Pearson Education Limited.

Verhees, F. J. H. ., Kupers, A., \& Klopcic, M. (2011). Entrepreneurial proclivity and farm performance: the cases of Dutch and Slovenian farmers. The International Journal of Entrepreneurship and Innovation, 12(3), p. 169177. https://doi.org/10.5367/ijei.2011.0039

World Population Review Privacy. (2017). World Population Review. Recuperado nov. 22, 2019, de http://worldpopulationreview.com/countries/india-population/

World Tourism Organization. (2019). Innovation and Rural Development Takes Center Stage For Ministers' Summit at World Travel Market. Recuperado November 26, 2019, de http://www2.unwto.org/press-release/201911-05/innovation-and-rural-development-takes-center-stage-ministers-summit-world-

Zai, C., \& Sahr, C. L. L. (2019). Touristic Route As A Tool For Territorial Development: The "Verde Que Te Quero Verde" Route In Campo Magro/Parana (Brasil). Finisterra, 11(8), p. 135-154. https://doi.org/10.18055/Finis13421

\section{Informação dos autores}

\section{Ivaneli Schreinert dos Santos}

Doutoranda do Programa de Pós-graduação em Turismo da Universidade de São Paulo. Mestra em Agronegócios pela Universidade Federal do Rio Grande do Sul (2020). Engenheira agrônoma pela Universidade Federal do Pelotas (2017) e Bacharela em Turismo pela Universidade Federal de Pelotas (2012). Atuou em projetos de pesquisa, ensino e extensão nessas instituições. Pesquisa na área de turismo, com temas associados a natureza, meio rural, aventura, gênero e produção do conhecimento, utilizando métodos de abordagens mistas qualitativas e quantitativas.

Contribuições para o trabalho: concepção da pesquisa, revisão da literatura, coleta de dados, análise de dados e discussão.

E-mail: ivaneli@usp.br

ORCID: https://orcid.org/0000-0002-7858-1015

\section{Camila Elisa dos Santos Alves}

Doutora em Agronegócios pela Universidade Federal do Rio Grande do Sul (2019). Bacharela em Administração pela Universidade Federal de Pelotas (2011) e Mestre em Administração pela Universidade Federal do Rio Grande do Sul (2015). Profissional com experiência em pesquisa, elaboração e ministração de aulas. Ampla capacidade analítica e desenvolvimento de conteúdo em diversas áreas.

Contribuições para o trabalho: revisão da literatura, coleta de dados, análise de dados e discussão.

E-mail: camilaelisaalves@gmail.com

ORCID: https://orcid.org/0000-0002-4033-6313

\section{Homero Dewes}

Pré e Pós-doutorado em análise de proteínas no Instituto Max-Planck de Bioquímica, Mastinsried-Munique (1975-1978 e 19901991). Doutor em Biologia pela University of California Los Angeles (1987). Mestre em Ciências Biológicas pela Universidade Federal do Rio Grande do Sul (1975). Graduado em Farmácia (1969) e Farmácia-Bioquímica (1971) pela Universidade Federal do Rio Grande do Sul. Atualmente professor titular do Departamento de Biofísica e professor orientador do Programa de PósGraduação em Agronegócios da Universidade Federal do Rio Grande do Sul.

Contribuições para o trabalho: concepção da pesquisa, revisão da literatura, coleta de dados, análise de dados e discussão.

E-mail: hdewes@ufrgs.br

ORCID: https://orcid.org/0000-0003-4043-6434 